\title{
World Health Organization Clinical Staging of HIV/AIDS for Adults and Adolescents Clinical Classification
}

National Cancer Institute

\section{Source}

National Cancer Institute. World Health Organization Clinical Staging of HIVIAIDS for

Adults and Adolescents Clinical Classification. NCI Thesaurus. Code C124713.

A standardized rating scale developed by the World Health Organization (WHO) in 2007, which is a classification system used for immunological staging of HIV/AIDS in adults and adolescents with established HIV infection. This instrument classifies HIV disease on the basis of clinical manifestations. 